\section{Enfermedad de Castleman unicéntrica renal}

Gómez-Sánchez J, Herrera-Muñoz J, Preciado-Estrella D, y colaboradores.

\section{Resumen}

ANTECEDENTES: la enfermedad de Castleman describe un grupo de alteraciones linfoproliferativas causada por la producción excesiva de citocinas proinflamatorias, principalmente por interleucina-6 (IL-6). Los pacientes manifiestan signos y síntomas clínicos heterogéneos, con hallazgos histopatológicos de nódulos linfáticos y disfunción orgánica múltiple.

CASO CLÍNICO: paciente masculino de 70 años de edad, con antecedente de diabetes tipo 2 e hipertensión arterial sistémica, diagnosticado de manera fortuita con quiste renal izquierdo Bosniak I y masa en la región pélvica ipsilateral de $36 \mathrm{~mm}$. El gamagrama renal reportó una tasa de filtrado glomerular de $22.5 \mathrm{~mL} / \mathrm{min}$ en el riñón derecho y de $39.3 \mathrm{~mL} / \mathrm{min}$ en el riñón izquierdo, por lo que se solicitó citología urinaria que resultó negativa. Los estudios de laboratorio reportaron: hemoglobina de $14.6 \mathrm{mg} / \mathrm{dL}$, hematocrito $38 \%$, leucocitos 7240, plaquetas 226000, TP 15.2, TTP $32 \mathrm{seg,} \mathrm{glucosa} 158 \mathrm{mg} / \mathrm{dL}$ y creatinina 0.7; el examen general de orina no mostró alteraciones. Se realizó nefrectomía radical sin registro de complicaciones tempranas o inmediatas, con adecuado control metabólico y hemodinámico, por lo que se otorgó el alta hospitalaria. El resultado histopatológico reportó tumor linfoplasmocitoide en el tejido adiposo del hilio renal $(3.5 \mathrm{~cm})$, compatible con enfermedad de Castleman.

CONCLUSIONES: la enfermedad de Castleman es una alteración difícil de diagnosticar, por lo que el estudio histopatológico es decisivo. Debido a su baja incidencia, aún no se establece el tratamiento adecuado; sin embargo, en las variantes unicéntricas la escisión quirúrgica es la única opción curativa.

PALABRAS CLAVE: enfermedad de Castleman, enfermedades linfoproliferativas, cáncer renal.

Rev Mex Urol. 2017 Sep-Oct;77(5):389-392.

\section{Renal unicentric Castleman's disease}

Gómez-Sánchez J, Herrera-Muñoz J, Preciado-Estrella D, et al.

Abstract

BACKGROUND: Castleman's disease describes a group of lymphoproliferative disorders caused by excessive proinflammatory cytokine production, mainly of interleukin-6. Patients present with heterogeneous clinical features, with histopathologic lymph node changes, and often with multiple organ failure.
División de Urología, Hospital General Dr. Manuel Gea González (SSA), Ciudad de México.

Recibido: diciembre 2016

Aceptado: julio 2017

Correspondencia

Dr. José Gómez Sánchez

chechemail@gmail.com

Este artículo debe citarse como

Gómez-Sánchez J, Herrera-Muñoz J, Preciado-Estrella $D, y$ col. Enfermedad de Castleman unicéntrica renal. Rev Mex Urol. 2017 sep-oct;77(5):389-392.

DOI: https://doi.org/10.24245/revmexurol.v77i5.1111 
CLINICAL CASE: A 70-year-old man had a past medical history of type 2 diabetes mellitus and high blood pressure. A left Bosniak I renal cyst and a 36-mm mass occupying the ipsilateral pelvic region were incidentally diagnosed. Kidney scintigram revealed a glomerular filtration rate of $22.5 \mathrm{~mL} / \mathrm{min}$ in the right kidney and of $39.3 \mathrm{~mL} /$ min in the left kidney. Complementary urinary cytology study was negative. Laboratory test results were: hemoglobin $14.6 \mathrm{mg} / \mathrm{dL}$, hematocrit 38\%, leukocytes 7240, platelets 226000, PT 15.2, PTT 32 sec, glucose $158 \mathrm{mg} / \mathrm{dL}$, creatinine 0.7 , and nonpathologic urinalysis. Radical nephrectomy was performed with no early or intermediate complications, metabolic control and hemodynamic control were adequate, and the patient was released. The histopathologic result was lymphoplasmacytic tumor in the adipose tissue of the renal hilum $(3.5 \mathrm{~cm})$ consistent with Castleman's disease.

CONCLUSIONS: Castleman's disease is difficult to diagnose. Histopathologic study is essential, and given the low frequency of the disease, ideal management has not been established. However, surgical excision is the only curative option in its unicentric variants.

KEYWORDS: Castleman's disease; Lymphoproliferative disorders; Kidney cancer
División de Urología, Hospital General Dr. Manuel Gea González (SSA), Ciudad de México.

Correspondence

Dr. José Gómez Sánchez chechemail@gmail.com

\section{ANTECEDENTES}

La enfermedad de Castleman describe un grupo de alteraciones linfoproliferativas, pobremente entendidas, causadas por la producción excesiva de citocinas proinflamatorias, principalmente por interleucina-6 (IL-6). Su descripción inicial fue en $1954 ;^{1}$ también se conoce como hiperplasia gigante de ganglios linfáticos, hamartoma de ganglios linfáticos, linforreticuloma folicular o linfoma gigante benigno. ${ }^{2}$ Esta enfermedad se divide en unicéntrica (cuando solo aparece una masa tumoral) o multicéntrica (con afección de linfadenopatía generalizada) y se subdivide en hialina vascular y de células plasmáticas.

Su clasificación se basa en los hallazgos histopatológicos de los ganglios afectados como: hialino-vascular, de células plasmáticas o mixta. ${ }^{3}$ El tipo hialino-vascular es asintomático y loca- lizado, cuyo tratamiento consiste en resección quirúrgica; la variante de células plasmáticas suele ser multicéntrica, incluso estar localizada $y$, en general, requiere tratamiento sistémico. Los pacientes que no reciben tratamiento suelen tener un mal pronóstico de la enfermedad. Las causas más frecuentes de mortalidad se asocian con infecciones, insuficiencia renal y neoplasias (linfoma y sarcoma de Kaposi). ${ }^{4}$ La enfermedad de Castleman suele ser resistente al tratamiento con esteroides o quimioterapia y requiere otro tipo de protocolos, ya sea interferón-alfa o anticuerpo monoclonal contra el antígeno CD20 rituximab. $^{5}$

\section{CASO CLÍNICO}

Paciente masculino de 70 años de edad, con antecedente de diabetes mellitus tipo 2 e hipertensión arterial sistémica, con tratamiento irregular, a quien de manera fortuita en una 
tomografía axial computada simple de abdomen se le detectaron un quiste renal simple Bosniak I cortical izquierdo y una masa en la región pélvica ipsilateral de $36 \mathrm{~mm} \times 28 \mathrm{~mm}$, con 16 Unidades Hounsfield, sin alteración obstructiva. El gamagrama renal DTPA reportó una tasa de filtrado glomerular de $22.5 \mathrm{~mL} / \mathrm{min}$ en el riñón derecho y de $39.3 \mathrm{~mL} / \mathrm{min}$ en el riñón izquierdo. La citología urinaria, solicitada como estudio complementario, resultó negativa.

Los estudios de laboratorio reportaron: hemoglobina de $14.6 \mathrm{mg} / \mathrm{dL}$, hematocrito $38 \%$, leucocitos 7240, plaquetas 226,000, TP 15.2, TTP 32 seg, glucosa $158 \mathrm{mg} / \mathrm{dL}$ y creatinina 0.7 . El examen general de orina mostró resultados dentro de los parámetros de referencia.

Se realizó nefrectomía radical izquierda, con sangrado aproximado de $500 \mathrm{~mL}$, sin complicaciones adicionales.

Durante la estancia hospitalaria tuvo adecuado control metabólico y hemodinámico, por lo que se otorgó el alta médica.

El resultado histopatológico reportó un tumor linfoplasmocitoide en el tejido adiposo del hilio renal $(3.5 \mathrm{~cm})$, compatible con enfermedad de Castleman (Figura 1).

El seguimiento trimestral no mostró alteraciones en los exámenes de laboratorio, ni clínicos.

\section{DISCUSIÓN}

La enfermedad de Castleman es un padecimiento raro, del que se ignora su incidencia real. Afecta por igual a hombres y mujeres y hasta la fecha no se ha descrito preferencia por alguna raza. ${ }^{5}$ Esta enfermedad se caracteriza por hiperplasia no clonal en los ganglios linfáticos. Clínicamente puede aparecer como un padecimiento localizado (unicéntrico) o multicéntrico.

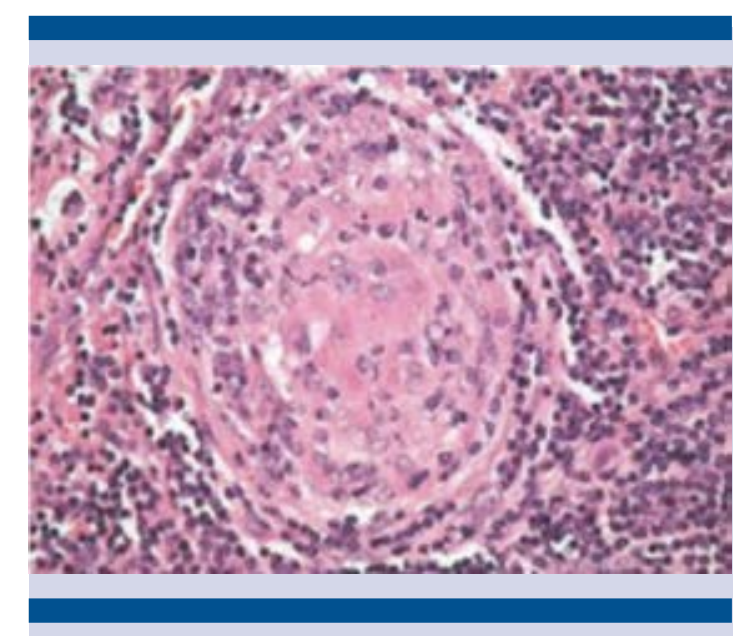

Figura 1. Centro germinal con depósito de material hialino y disposición en "capas de cebolla" de células del manto (H-E 250 X).

Es importante diferenciar ambos tipos de la enfermedad de Castleman: hialino-vascular o de células plasmáticas, pues pertenecen a diferente morfología y clínica. El tipo más frecuente es el hialino-vascular, que se distingue por folículos con zona del manto muy ensanchada, dispuestos en capas concéntricas, aspecto en "tela de cebolla" y con uno o dos centros germinales con notable hiperplasia de las células foliares dendríticas y un vaso sanguíneo de pared gruesa, hialinizada, que entra perpendicular al centro germinal. La zona interfolicular muestra hiperplasia notable de los vasos sanguíneos y las células plasmáticas son escasas. Las células plasmáticas pueden tener folículos linfoides, semejantes a los del tipo hialino-vascular, y la principal característica es la plasmocitosis, con mantos de células plasmáticas que dilatan los sinusoides y pueden encontrarse en la zona paracortical e interfolicular.

Desde el punto de vista clínico, el tipo hialinovascular no expresa síntomas y casi siempre se localiza en alguna región ganglionar, como el mediastino. El tipo de células plasmáticas también puede ser localizado; sin embargo, 
suele ser multicéntrico y los pacientes muestran hipergamaglobulinemia policlonal y, en ciertas ocasiones, manifiestan síntomas generales.

Hasta la fecha no se ha descrito ningún mecanismo implicado en la patogénesis y evolución de la enfermedad de Castleman. El tipo de CD se ha relacionado con algunos virus, como el herpes virus tipo 8 (HHV-8). También se ha evaluado la participación citocinas específicas o colonias de linfocitos $B$, pero no se tienen datos concluyentes. ${ }^{6,7}$

Los pacientes con variedad hialino-vascular unicéntrica pueden permanecer asintomáticos por meses o años, ${ }^{1,4,5}$ o expresar manifestaciones locales (dolor secundario al crecimiento tumoral).

Por lo que se refiere a las opciones de tratamiento, estas se basan en pequeñas series de pacientes, resultados obtenidos en padecimientos similares u opiniones de expertos. En la mayoría de los pacientes con enfermedad de Castleman unicéntrica se obtiene una biopsia escisional y cuando no es factible, puede indicarse radioterapia. ${ }^{8,9}$ La enfermedad de Castleman multicéntrica requiere tratamiento sistémico.

El estudio histológico es decisivo en la evaluación de neoplasias ganglionares y diferenciación de los subtipos de la enfermedad de Castleman, con la finalidad de establecer el tratamiento oportuno, evitar el deterioro clínico de los pacientes y que se diagnostiquen con enfermedad avanzada. En las variantes unicéntricas la escisión quirúrgica es la única opción curativa.

\section{Conflicto de interés}

No existe conflicto de interés.

\section{REFERENCIAS}

1. Castleman B, Towne V. Case records of the Massachusetts General Hospital: Case no 40231. N Engl J Med 1994;250:1001-1005.

2. Bowne J, Lewin JJ, Filippa DA, et al. The management of unicentric and multicentric Castleman's disease. A report of 16 cases and a review of the literature. Cancer 1999;85:706-717.

3. Keller AR, Hochholzer L, Castleman B. Hyaline-vascular and plasma-cell types of giant lymph node hyperplasia of the mediastinum and other locations. Cancer 2002;29:670-683.

4. Frizzera G, Peterson BA, Bayrd ED, et al. A systemic lympho-proliferative disorder with morphologic features of Castleman's disease: clinical findings and clinicopathologic correlations in 15 patients. J Clin Oncol 1985;3:1202-1216.

5. Roca B. Castleman's disease. A Review. AIDS Rev 2009;11:37.

6. Casper C. New approaches for the treatment of human herpes virus 8-associated disease. Rev Med Virol 2008;18:321-329.

7. Candelaria M, Luna-Ochoa E, Labardini-Mendez J, et al. Virus y neoplasias hematológicas. Rev del Instituto Nacional de Cancerología 2009;4:217-235.

8. Dham A, Peterson B. Castleman disease. Curr Opin Hematol 2007;14:354-359.

9. Cronine D, Warneke WA. Castleman's disease. An update on classification and the spectrum of associated lesions. Adv Anat Pathol 2009;16:236-246. 